\title{
Rollover instability of precast girders subjected to wind load
}

\section{Jong-Han Lee}

Department of Civil Engineering, Daegu University, Gyeongsan, Gyeongbuk, Republic of Korea

\section{Ilker Kalkan}

Department of Civil Engineering, Kirikkale University, Kirikkale, Turkey Jong-Jae Lee

Department of Civil and Environmental Engineering, Sejong University, Seoul, Republic of Korea

\section{Jin-Hwan Cheung \\ Department of Civil Engineering, Pusan National University, Busan, Republic of Korea (corresponding author: cheung@pusan.ac.kr)}

The use of longer and deeper precast concrete girders has created concern regarding their rollover instability, particularly during construction. Current design and construction specifications do not provide any specific guidelines that can be used to evaluate the rollover instability of a girder. Therefore, analytical and simplified numerical studies were performed to evaluate the critical wind load, lateral displacement and rotational angle that would induce rollover instability of a girder supported on an elastomeric bearing pad. The influence of the length and section properties of the girder on rollover instability was also investigated. The analytical method proposed in this study can be effectively used for evaluating the lateral behaviour and rollover instability of bridge girders and can also provide management values for securing the lateral stability of girders. The paper also provides a worked problem for a long-span typical European girder to determine critical values with application of the proposed method.

\section{Notation}

$A \quad$ area of bearing pad

$A_{i} \quad$ tributary area of bearing pad

$E \quad$ modulus of elasticity of girder

$E_{\text {ap }} \quad$ apparent modulus of elasticity of elastomer

$E_{\mathrm{b}} \quad$ bulk modulus of elasticity of elastomer

$E_{\mathrm{s}} \quad$ compressive modulus of elasticity of bearing pad

$e_{\mathrm{i}} \quad$ initial lateral eccentricity of girder

$F_{\text {cr }} \quad$ critical wind load per unit length

$F_{\mathrm{w}} \quad$ wind load per unit length

$f_{\mathrm{c}}^{\prime}$

$G$

$H_{\mathrm{b}}$

$h_{i}$

$h_{\mathrm{rt}}$

$I_{x}$

$I_{y}$

$J$

$k_{i}$

$k_{\mathrm{r}}$

$k_{\mathrm{v}}$

L

$L_{\mathrm{b}}$

$r$

$S_{i}$

$T_{\text {high }}$

$T_{\text {low }}$

$W_{\mathrm{b}}$

$w$ $w L$

$(w L)_{\mathrm{cr}}$

$y_{\mathrm{c}}$

$z_{0}$

$z_{0}^{\prime}$

$\alpha$

$\alpha_{\mathrm{t}}$

$\Delta_{\mathrm{s}}$

$\delta_{\mathrm{cr}}^{0}$

$\varepsilon_{\text {crsh }}$

$\theta_{\mathrm{s}}$

$\theta_{\mathrm{cr}}^{\mathrm{s}}$

$\theta_{\mathrm{s}}^{\max }$

$\sigma_{\mathrm{s}}$ total self-weight of girder critical self-weight of girder

height of centre of gravity of girder

average lateral flexural deflection

lateral flexural displacement

tilt angle of support

coefficient of thermal expansion

maximum shear deformation of bearing pad at service limit state

critical lateral displacement at mid-span

total creep and shrinkage strain

rotational angle at support

critical rotational angle at support

maximum rotational angle at support

average compressive stress of bearing pad

\section{Introduction}

Precast concrete bridge girders have been widely used in bridge design and construction as they provide ease and speed of construction along with excellent structural performance. The development of high-strength and precast prestressed concrete has led to the use of longer and deeper concrete girders, which has raised concerns about the rollover instability of the girders, particularly during construction. In recent years, the collapse of precast concrete bridge girders during construction in Pennsylvania indicated that a large initial lateral deformation (sweep) could cause an overturning moment to the girder and increase the possibility of lateral instability failure (Hurff and 
Kahn, 2012). Furthermore, Oesterle et al. (2007), who investigated another collapse accident of bridge girders in Arizona, concluded that the lateral instability of the girders was strongly attributed to the lateral displacement caused by factors such as initial sweep, support slope and thermal movement. The recent collapses of such long precast bridge girders has thus prompted an awareness of the rollover instability of concrete and prestressed beams. The stability problem has also become a major issue in various types of structures such as composite columns, precast concrete walls and foamed concrete (Han et al., 2013; Jones et al., 2016; Yooprasertchai et al., 2016).

Regarding the lateral stability of precast concrete beams, Mast $(1989,1993)$ proposed a method to calculate the lateral safety of a beam during lifting and transportation using the ratio of the resisting moment of the elastic support to the overturning moment caused by the sweep and self-weight of the beam. The method proposed by Mast $(1989,1993)$ is the only analytical method specified in the design standard of the Precast/Prestressed Concrete Institute's (PCI) Bridge Design Manual (BDM) (PCI, 2003). However, the analytical method requires assumption of the critical rotational angle of the girder at the support. The PCI BDM and current design and construction specifications (Aashto, 2004, 2007, 2010) require construction contractors to secure the lateral stability of precast members, but they do not provide any guidelines to evaluate the lateral stability of a beam on an elastic bearing support.

Recently, for a precast I-girder supported on an elastic bearing, Lee (2012a) examined the lateral behaviour and instability of the girder under a combination of initial geometry imperfections and environmental thermal effects. To analyse the lateral movement induced by various environmental conditions, the lateral thermal gradient and an analytical method for precast I-girders were proposed (Lee, 2012b; Lee and Kalkan, 2012). In addition, Hurff and Kahn (2012) carried out an experimental and analytical study on the lateral instability of a $30 \mathrm{~m}$ long precast prestressed concrete bridge girder. Vidigal de Lima and El Debs (2005) and Kim et al. (2014) evaluated the torsional behaviour and lateral stability of prestressed concrete beams. Few studies have been conducted on the lateral behaviour and instability of precast concrete girders using both experimental and analytical methods, because such studies are rather complicated due to the presence of various imperfect factors, such as the geometry, material and support conditions.

These difficulties increase the need for a numerical method that can be used to evaluate the effects of various factors on the three-dimensional (3D) behaviour of structures, including the lateral stability of precast concrete girders (Atta and El-Shafiey, 2014; Guiglia et al., 2013; Heiza, 2013; Hou et al., 2016; Lee et al., 2015; Mullapudi and Ayoub, 2013; Najafian et al., 2013). In general, 3D solid and shell element models are used to evaluate the lateral behaviour and instability of bridge girders supported on an elastic bearing pad. Barsoum and Gallagher (1970) solved lateral and torsional flexural stability problems using finite-element (FE) analysis, and several other researchers (Li et al., 2002; Rengarajan et al., 1985; Talbot and Dhatt, 1987) developed the FE method using shell elements for stability problems, which require geometric nonlinearity and unstable bifurcation. In the current study, for much easier modelling of the elastic support condition and application to changes in girder geometry and boundary conditions, a simplified numerical method, based on a 3D beam element, was used to evaluate the lateral instability behaviour of precast concrete girders supported on elastomeric bearings at the construction stage. For verification, the proposed beam model was compared with 3D FE models using solid and shell elements.

Along with the results of the numerical analysis, an analytical equation was developed to evaluate the critical wind load and lateral displacement that can induce rollover instability of a girder. The construction and loading conditions in this study were the stage when a girder is placed on an elastic bearing pad and subjected to lateral wind load prior to placement of the lateral bracing and concrete deck. Therefore, the lateral wind load, which is considered a significant external force to induce lateral instability in a precast girder, was combined with the self-weight of the girder. In addition, this study accounted for the effects of the length and section properties of the girder on its rollover instability. As a result, the proposed analytical method can be effectively applied to evaluate the lateral behaviour and instability of precast concrete I-girders, and provides construction management values for the critical wind load, displacement and rotational angle.

\section{Literature review of analytical approaches to the rollover stability of girders}

An analytical method for evaluation of the lateral stability of a slender beam during handling and transportation was initially proposed by Laszlo and Imper (1987) and later expanded on by Mast $(1989,1993)$. As noted earlier, the proposed method is accepted in the PCI BDM (PCI, 2003). For a beam supported on an elastic bearing pad or support, the equilibrium rotational angle at the support $\left(\theta_{\mathrm{s}}\right)$ due to initial imperfections at the support and in the girder can be obtained from

$$
\text { 1. } \theta_{\mathrm{s}}=\frac{\alpha r+e_{\mathrm{i}}}{r-y_{\mathrm{c}}-z_{0}}
$$

where $\alpha$ is the tilt angle of the support, $e_{\mathrm{i}}$ is the initial lateral eccentricity of the beam, $y_{\mathrm{c}}$ is the height of the centre of gravity of the beam, $z_{0}$ is the average of lateral flexural deflection due to the self-weight of the beam at the centre of gravity of the deflected shape of the beam, and $r$ is the radius of 
stability, defined as the ratio of the rotational constant of the elastic support to the self-weight of the beam. Therefore, the safety factor (SF) against rollover failure is calculated using the ratio of the resisting moment to the overturning moment

2. $\mathrm{SF}=\frac{r\left(\theta_{\mathrm{s}}^{\max }-\alpha\right)}{y_{\mathrm{c}} \theta_{\mathrm{s}}^{\max }+e_{\mathrm{i}}+z_{0}^{\prime} \theta_{\mathrm{s}}^{\max }}$

where $\theta_{\mathrm{s}}^{\max }$ and $z_{0}^{\prime}$ are, respectively, the maximum rotational angle at the support and the lateral flexural displacement in the beam when rollover instability occurs. According to the PCI BDM (PCI, 2003), the lateral displacement is calculated based on an assumption of the effective stiffness of the beam when the top flange tensile stress exceeds $0 \cdot 63\left(f_{c}^{\prime}\right)^{1 / 2}$

3. $z_{0}^{\prime}=z_{0}\left(1+2 \cdot 5 \theta_{\mathrm{s}}^{\max }\right)$

However, the lateral flexural displacement of the beam, $z_{0}^{\prime}$, and the rotational angle at the support, $\theta_{\mathrm{s}}^{\max }$, cannot be obviously determined. The PCI BDM (PCI, 2003) recommends 0.4 rad for the rotational angle at the cracking failure of a beam on flexible support. The lateral flexural displacement of the beam and the rotational angle of the beam, which are crucial for evaluating the beam's lateral stability, should be based on the rollover equilibrium of the beam, not on the strength of the beam. Moreover, the analytical method is based on the ratio of the resisting moment to the overturning moment caused by the self-weight of the girder alone.

To analytically calculate the critical self-weight of the girder related to its rollover instability on an elastic bearing pad, Burgoyne and Stratford $(1999,2001)$ proposed the equation

4. $(w L)\left[y_{\mathrm{c}} \sin \theta_{\mathrm{s}}+\frac{w \sin \theta_{\mathrm{s}} L^{4}}{120 E I_{y}} \cos \theta_{\mathrm{s}}\right]=2 k_{\mathrm{r}} \theta_{\mathrm{s}}$

where $w$ is the self-weight of the girder per unit length, $L$ is the length of the girder, $E$ and $I_{y}$ are the modulus of elasticity and moment of inertia in the weak axis, respectively, and $k_{\mathrm{r}}$ is the rotational stiffness of the elastic bearing pad.

With a small angle at the support, the critical self-weight of the girder is

5. $(w L)_{\mathrm{cr}}=\frac{2 k_{\mathrm{r}}}{y_{\mathrm{c}}+\left(w L^{4} / 120 E I_{y}\right)}$

The aforementioned analytical studies are all based on the self-weight of the girder. The rollover instability of the girder is strongly associated with the lateral wind load. Therefore, the following analytical equation, composed of the overturning moment caused by the wind load and self-weight of the girder, was derived.

$$
\begin{aligned}
& (w L)\left[y_{\mathrm{c}} \sin \theta_{\mathrm{s}}+\frac{w \sin \theta_{\mathrm{s}} L^{4}}{120 E I_{y}} \cos \theta_{\mathrm{s}}+\frac{F_{\mathrm{w}} \cos \theta_{\mathrm{s}} L^{4}}{120 E I_{y}} \cos \theta_{\mathrm{s}}\right] \\
& +\left(F_{\mathrm{w}} L\right)\left[y_{\mathrm{c}} \cos \theta_{\mathrm{s}}-\frac{w \sin \theta_{\mathrm{s}} L^{4}}{120 E I_{y}} \sin \theta_{\mathrm{s}}-\frac{F_{\mathrm{w}} \cos \theta_{\mathrm{s}} L^{4}}{120 E I_{y}} \sin \theta_{\mathrm{s}}\right] \\
& =2 k_{\mathrm{r}} \theta_{\mathrm{s}}
\end{aligned}
$$$$
6 .
$$

where the first terms in square brackets represent the rigidbody rotation at the support, and the second and third terms are the average flexural lateral displacements caused by the self-weight of the girder and the wind load $\left(F_{\mathrm{w}}\right)$, respectively. Since the rotational angle at the support is small, Equation 6 can be simplified as

7.

$$
\begin{aligned}
& (w L)\left[y_{\mathrm{c}} \theta_{\mathrm{s}}+\frac{w \theta_{\mathrm{s}} L^{4}}{120 E I_{y}}+\frac{F_{\mathrm{w}} L^{4}}{120 E I_{y}}\right] \\
& +\left(F_{\mathrm{w}} L\right)\left[y_{\mathrm{c}}-\frac{F_{\mathrm{w}} L^{4}}{120 E I_{y}} \theta_{\mathrm{s}}\right]=2 k_{\mathrm{r}} \theta_{\mathrm{s}}
\end{aligned}
$$

In order to obtain the solution to Equation 7, the critical rotational angle at the support, at which rollover instability of the girder occurs, should be defined. However, experimental investigations into the critical rotational angle are a very challenging task due to instrumentation and measurement difficulties, as well as geometric, material and support conditions. Therefore, to determine the critical rotational angle at the support, a numerical method was employed to assess the lateral behaviour and rollover instability of a girder subjected to a combination of wind load and girder self-weight.

\section{Three-dimensional FE models for analysis of lateral behaviour of precast concrete I-girders}

\section{FE models of bridge girders}

The lateral behaviour of bridge girders, particularly I-girders supported on elastic bearing pads, is generally examined using 3D FE models consisting of solid and shell elements. Figure 1 shows the 3D solid and shell element models for an Aashto (American Association of State Highway and Transportation Officials) standard type V girder of length $40 \mathrm{~m}$ in Abaqus/ CAE 6.10 (Dassault Systems Simulia, Providence, RI, USA). The size of the element was approximately $10 \mathrm{~cm}$ and, for both ends of the girder supported on the bearing support, it was refined into 10 elements along the width and length of the bearing. Therefore, the total numbers of solid and shell FEs used to model the $40 \mathrm{~m}$ long type $\mathrm{V}$ girder were 43056 and 17388 , respectively.

In addition, the precast concrete bridge girders included a prestressing force to generate a camber, which could affect the girder's rollover instability. Therefore, in this study, a static analysis was carried out to produce the camber of the girder, 

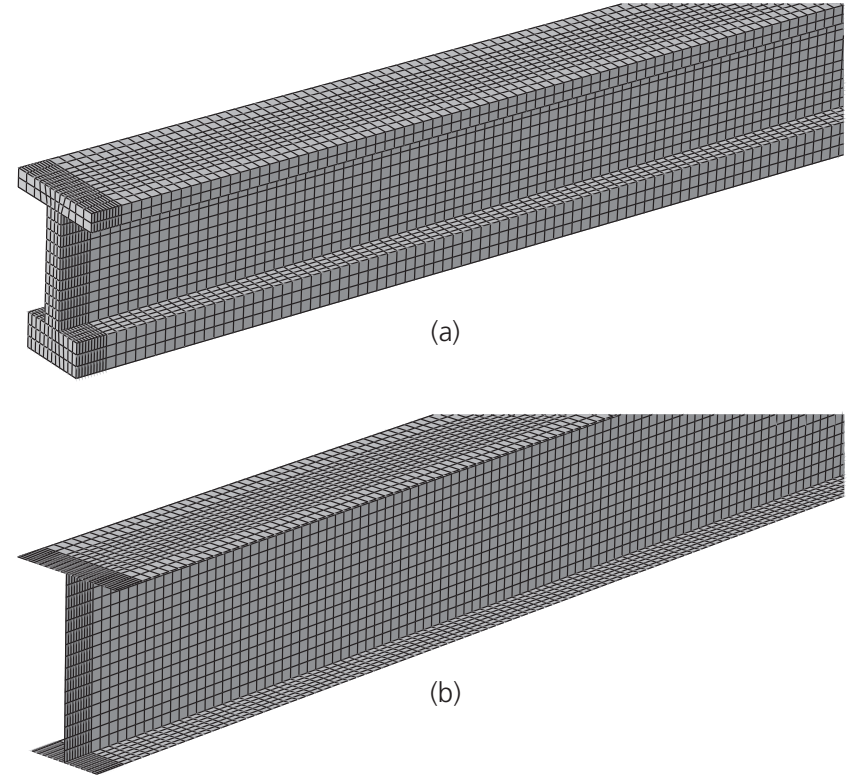

Figure 1. 3D FE models of type $V$ girder: (a) solid FE model; (b) shell FE model

which compensated for the vertical deflection caused by the self-weight of the girder in order to eliminate the influence of camber in the rollover instability of the girder. That is, the initial vertical camber of the girder was zero due to the selfweight and the prestressing force of the girder.

\section{Modelling the elastic bearing support}

With their advantages of constructability and maintenance, elastomeric bearing pads have been widely used to support precast concrete bridge girders. In particular, long-span precast concrete bridge girders such as Aashto type V, type VI and 'bulb tee' beams utilise steel-reinforced elastomeric bearing pads (FDoT, 1997; GDoT, 2005) to resist the vertical loads caused by the dead and live loads of a bridge. Steel-reinforced elastomeric bearings can be designed using either method A or method B described in section 14 of the Aashto LRFD specifications (Aashto, 2007, 2010). The stress limits associated with method A normally result in a lower capacity than those using method B. Therefore, the use of method B requires an additional test and quality control. Thus, most states in the USA, including Georgia, Texas and Wisconsin (GDoT, 2005; TxDoT, 2012; WisDoT, 2014), recommend the use of method A described in Aashto LRFD section 14.7.6 (Aashto, 2007, 2010) to design elastomeric bearing pads. Accordingly, in this study, the size of the steel-reinforced elastomeric bearing pad was determined using method $\mathrm{A}$ of the Aashto LRFD specifications.

The design of an elastomeric bearing pad basically involves the design loads, including dead and live loads at the service limit state. In addition to the resistance to the design load, the size of the steel-reinforced elastomeric bearing secures the stability of the girder, for which the Aashto LRFD specifications state that the total thickness of the pad shall not exceed the lesser of one third of the width or length of the pad. In fact, the larger the width of the bearing pad, the more secure the stability of the girder. Therefore, the width of the bearing pad for a type $\mathrm{V}$ girder was determined to be $600 \mathrm{~mm}$, considering a minimum clearance of $50 \mathrm{~mm}$ (GDoT, 2005). Subsequently, the length of the bearing pad was determined iteratively to satisfy the average compressive stress limits as follows

8. $\sigma_{\mathrm{s}} \leq 8.6 \mathrm{MPa}$ and $\sigma_{\mathrm{s}} \leq 8.6 G S_{i}$

where $G$ is the shear modulus of the elastomer and $S_{i}$ is the shape factor of the bearing pad, which, for a rectangular shape, can be calculated from

9. $S_{i}=\frac{L_{\mathrm{b}} W_{\mathrm{b}}}{2 h_{i}\left(L_{\mathrm{b}}+W_{\mathrm{b}}\right)}$

where $L_{\mathrm{b}}$ and $W_{\mathrm{b}}$ are the length and width of the bearing pad, respectively, and $h_{i}$ is the thickness of the $i$ th elastomeric layer in the bearing. In addition, a limiting value of 20 for $S_{i}^{2} / n$, in which $n$ is the number of interior layers of elastomer, in the revision of the Aashto LRFD specifications (Aashto, 2010) for steel-reinforced elastomeric bearings, was also accounted for in this study.

The total elastomer thickness of the pad, $h_{\mathrm{rt}}$, which also affects the deflection and stability of the bearing pad, was determined using

10a. $h_{\mathrm{rt}} \geq 2 \Delta_{\mathrm{s}}$

10b. $\quad H_{\mathrm{b}} \leq \operatorname{smaller}\left(L_{\mathrm{b}} / 3, W_{\mathrm{b}} / 3\right)$

where $H_{\mathrm{b}}$ is the total thickness of the bearing pad and $\Delta_{\mathrm{s}}$ is the maximum shear deformation of the pad at the service limit state, which can be calculated from $65 \%$ of the design thermal movement range combined with the movements caused by creep and shrinkage. According to section 3 of the Aashto LRFD specifications (Aashto, 2007, 2010), the high and low design temperatures, $T_{\text {high }}$ and $T_{\text {low }}$, for concrete structures in moderate climate conditions are $-12^{\circ} \mathrm{C}$ and $27^{\circ} \mathrm{C}$, respectively. Therefore, with the assumption of total creep and shrinkage strain $\left(\varepsilon_{\mathrm{crsh}}\right)$ of 0.0003 (WisDoT, 2014), the maximum shear deformation of the bearing pad can be calculated from

11. $\Delta_{\mathrm{s}}=\left[0.65\left(T_{\text {high }}-T_{\text {low }}\right) \alpha_{\mathrm{t}}+\varepsilon_{\text {crsh }}\right] L$

where $\alpha_{\mathrm{t}}$ is the coefficient of thermal expansion $\left(=10 \cdot 8 \times 10^{-6}\right)$. 
Based on a value of 50 for the durometer hardness with a shear modulus of $0.7 \mathrm{MPa}$, the steel-reinforced elastomeric bearing pad for the Aashto type $\mathrm{V}$ girder was designed to be $600 \mathrm{~mm}$ wide, $300 \mathrm{~mm}$ long and $60 \mathrm{~mm}$ high. The steelreinforced elastomeric bearing pad was composed of three internal layers, each $6 \mathrm{~mm}$ thick, and two external layers, each $12 \mathrm{~mm}$ thick, which satisfied the requirement that the external elastomeric layers shall be no thicker than $70 \%$ of the internal layers (Aashto, 2007, 2010).

For numerical analysis, it is important to evaluate the vertical stiffness of the bearing pad, because an elastomeric bearing pad supports the vertical load by its vertical stiffness. According to Yazdani et al. (2000, 2003), the vertical stiffness values calculated from the Aashto LRFD specifications (Aashto, 2007, 2010) agreed well with those obtained from FE analyses. Therefore, the vertical stiffness of the bearing pad was calculated using the compressive modulus of elasticity obtained from the Aashto LRFD specifications. With the defined bearing pad, the vertical stiffness of the bearing pad, $k_{\mathrm{v}}$, was derived as

12. $k_{\mathrm{v}}=\frac{E_{\mathrm{s}} A}{h_{\mathrm{rt}}}$

where $A$ is the area of the bearing pad, $h_{\mathrm{rt}}$ is the total elastomer thickness of the bearing pad and $E_{\mathrm{s}}$ is the effective compressive modulus of elasticity, which can be obtained using the stressstrain curves of an elastomer layer (figure C14.7.6.3.3-1 provided in the Aashto LRFD specifications (Aashto, 2007, 2010) for a steel-reinforced bearing pad based on the durometer hardness and shape factor. According to the stress-strain curves provided in the Aashto LRFD specifications (Aashto, 2007, 2010), the stress becomes stiffer as the strain increases. Therefore, the modulus of elasticity $E_{\mathrm{s}}$ was defined as being bilinear at a $3 \%$ compressive strain. Therefore, the modulus of elasticity was determined as $140 \mathrm{MPa}$ until a strain value of 0.03 strains and $180 \mathrm{MPa}$ beyond this strain. Figure 2 presents the bilinear relationship between the compressive stiffness and strain with the defined modulus of elasticity of the bearing pad. In Europe, EN 1337-3 (CEN, 2005) is commonly used to design elastomeric bearing pads. The EN 1337-3 method is similar to the procedure in the Aashto specifications but somewhat different in the calculation of the vertical modulus of elasticity in the case of no experimental testing on the bearing pad. The design of the bearing pad according to EN 1337-3 (CEN, 2005) will be treated in a worked problem later in the paper.

The vertical bearing stiffness of the elastomeric bearing pad was modelled using a series of non-linear springs, which react only under compression, because elastomeric bearing pads barely provide restraint when being uplifted. The compressive stiffness of an individual bearing spring, $k_{i}$, as suggested in previous research (Lee, 2012a), was calculated using the tributary area of the spring, $A_{i}$, according to the location of the

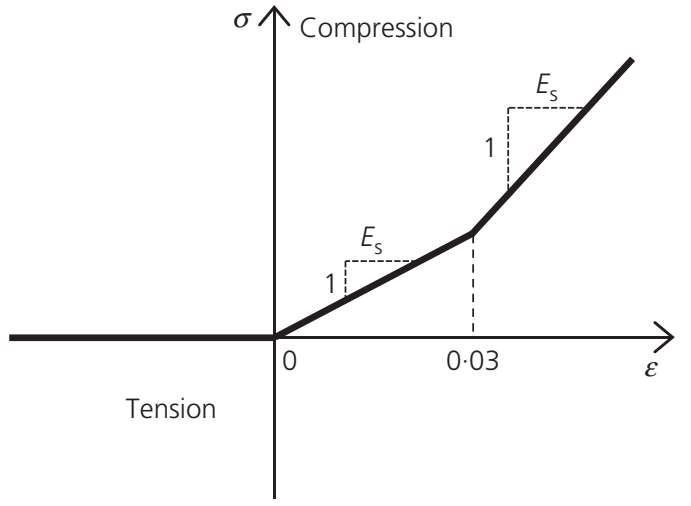

Figure 2. Bilinear relationship between compressive stress and strain for the elastomeric bearing pad used in this study

spring, as shown in Figure 3

13. $k_{i}=\frac{A_{i}}{A} k_{\mathrm{v}}$

\section{Proposed numerical method}

\section{Numerical model}

For easier numerical modelling of the elastic bearing support and application to changing conditions in the girder and bearing pad, a simplified numerical model was employed for evaluating the lateral behaviour and instability of a girder supported on an elastic bearing. Figure 4 shows the proposed numerical model for a $40 \mathrm{~m}$ long Aashto type $\mathrm{V}$ girder. The bridge girder was modelled using beam elements through the mid-height of the girder, to which a lateral force, relating mainly to the rollover instability of the girders, particularly during construction, could be easier to apply. The elastomeric bearing pad was modelled using non-linear spring elements, providing restraint only when compressed, similar to that defined in the solid and shell element models, as shown in Figure 4. The compressive stiffness of the individual bearing spring was calculated using the tributary area of the spring. In addition, the bearing pad is restrained by the rigid top and bottom plates. Therefore, rigid elements are used to connect the top nodes of the bearing spring elements, which are modelled through the width of the bearing pad, and no translational boundary conditions are assigned to the bottom nodes. Furthermore, a rigid element is used to connect the beam element of the girder and the spring element of the bearing pad at both ends. The elastomeric bearing pad subjected to a lateral force can have slight movement with its frictional resistance to the girder's movement. In this study, the small amount of horizontal frictional resistance was conservatively ignored.

\section{Procedure for numerical analysis}

The lateral instability of girders is dependent mainly on lateral wind load. Therefore, the lateral behaviour and instability 


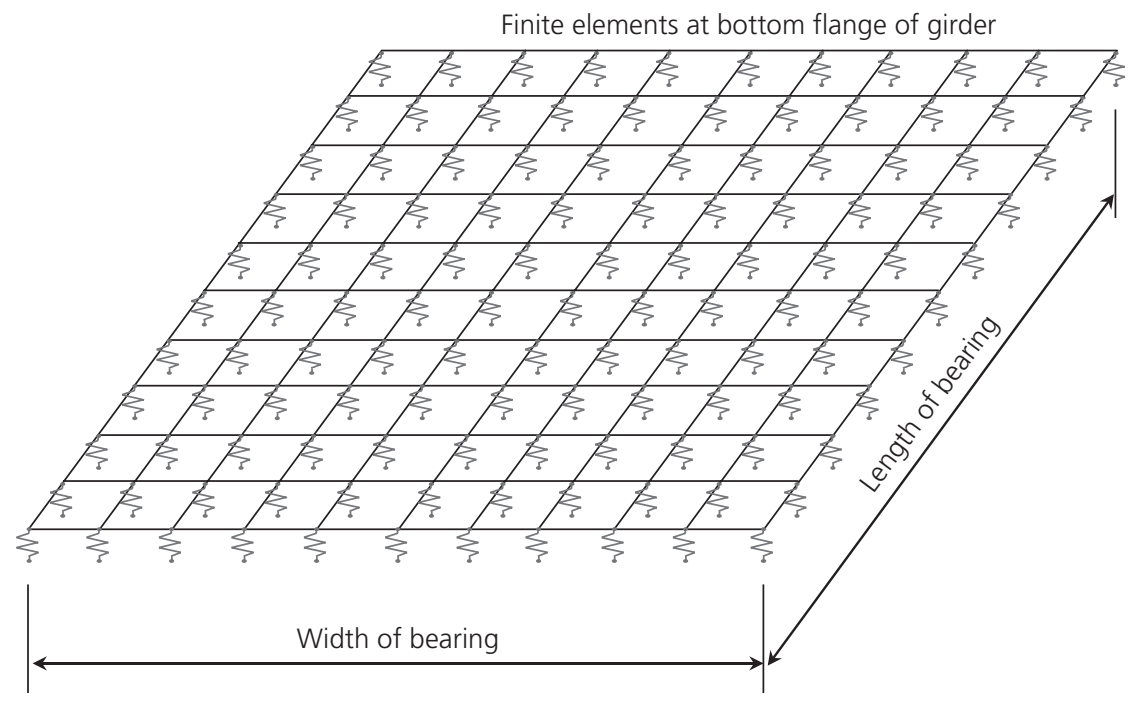

Figure 3. Numerical modelling of the elastomeric bearing pad in the 3D solid and shell FE models

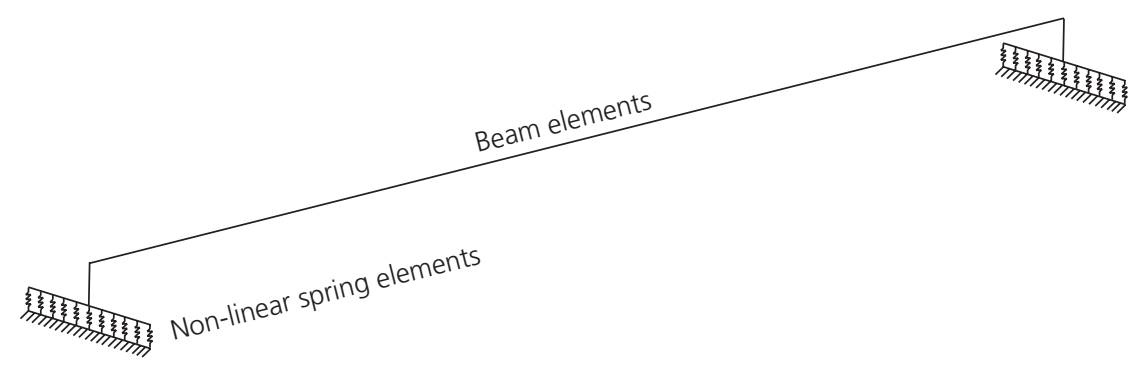

Figure 4. Proposed numerical model for the precast concrete

I-girder on the elastomeric bearing pad

of the girder on the elastic support were evaluated for increases in lateral wind load. A flowchart of the numerical analysis proposed in this study is given in Figure 5. A static analysis was first performed using an equivalent upward distributed force to generate the initial camber of the girder produced by the prestressing force. The girder with camber caused by the prestressing force was rested on the elastomeric bearing pad, which means that the non-linear elastomeric springs were adopted as a girder support. Subsequently, the self-weight of the girder was applied to represent the initial stress state of the elastomeric bearing pad. In this study, to eliminate the influence of camber on the lateral behaviour of the girder, the magnitude of the prestressing force corresponded to the deflection caused by the self-weight of the girder. Finally, the lateral wind force was applied to the beam elements until rollover collapse of the girder occurred. Numerical analysis accounts for the geometry non-linearity of the girder and the boundary non-linearity of the elastic support.

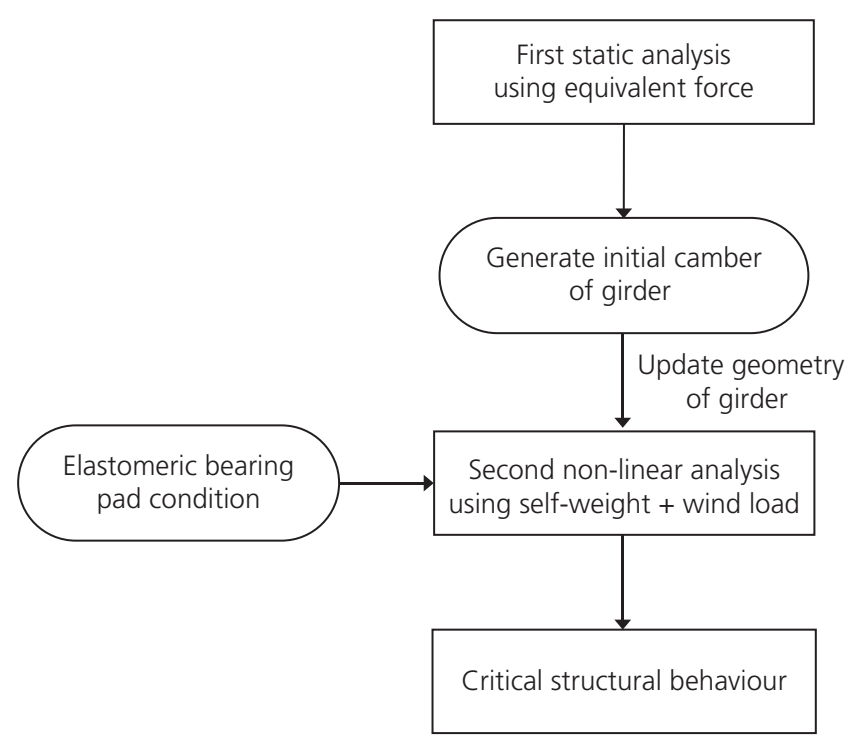

Figure 5. Flowchart of the proposed numerical analysis 


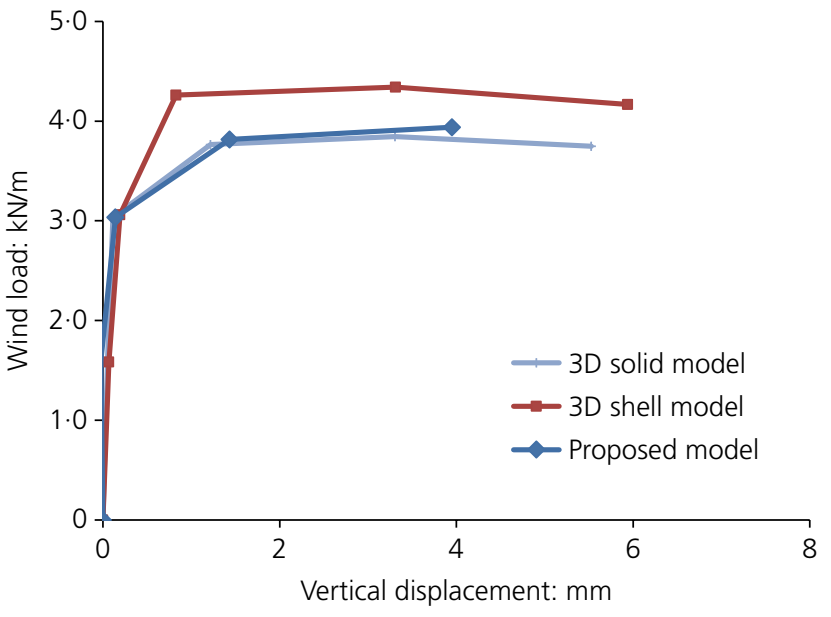

(a)

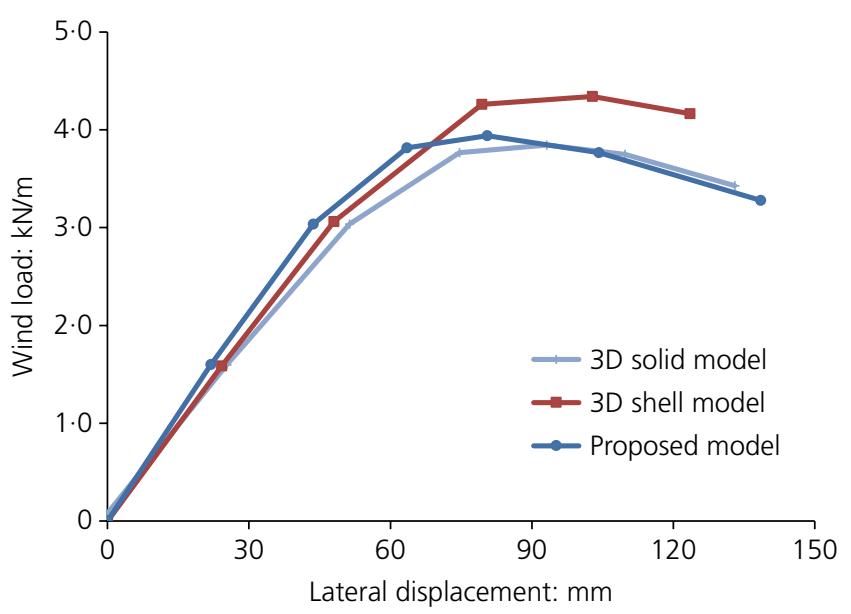

(b)

Figure 6. Wind load and (a) vertical displacement and (b) lateral displacement curves at mid-span

\section{Verification of the proposed numerical method}

The results obtained from the proposed numerical method were compared with those from the 3D FE models using solid and shell elements. Figure 6 shows the vertical and lateral displacement curves with increasing wind load for the three numerical models of the $40 \mathrm{~m}$ long type $\mathrm{V}$ girder at mid-span. The proposed numerical model shows good agreement with both the 3D solid and shell element models. The shell element model, which has additional stiffness at the intersection of the web and flange, was somewhat stiffer than the other numerical models. The rotational angles also showed good agreement between the solid FE model and the proposed numerical model, as shown in Figure 7. According to Figures 6 and 7, the girder is in a stable condition up to a wind load of approximately $3.0 \mathrm{kN} / \mathrm{m}$. After that, the lateral displacement and rotational angle increase, resulting in complete failure at approximately $3.8 \mathrm{kN} / \mathrm{m}$ wind load for the proposed numerical and solid element models and $4.3 \mathrm{kN} / \mathrm{m}$ for the shell $\mathrm{FE}$

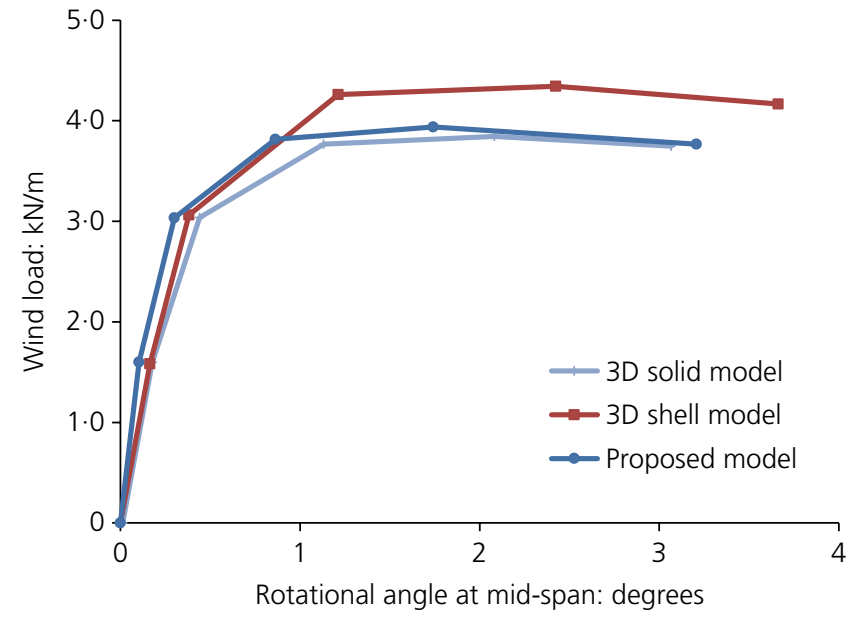

(a)

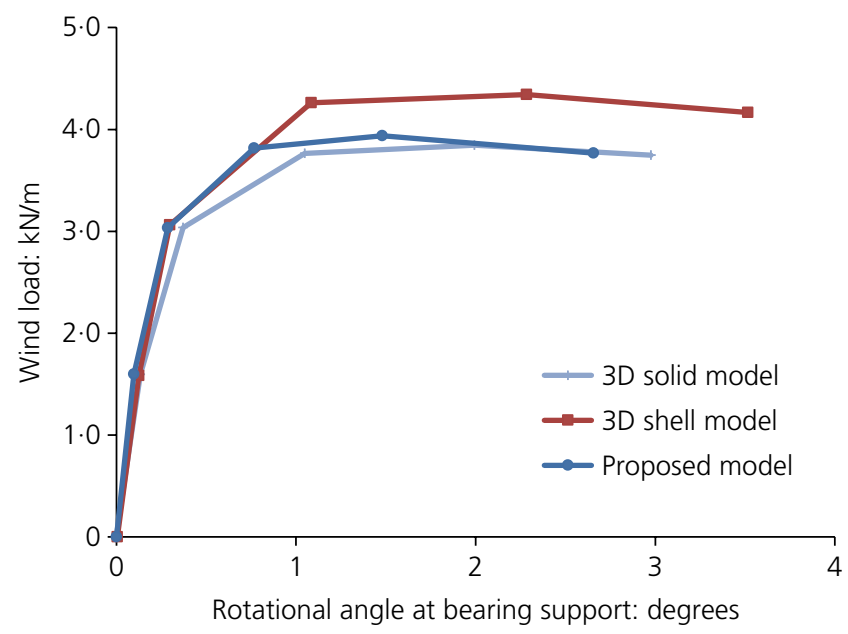

(b)

Figure 7. Rotational angle at (a) mid-span and (b) support with increasing wind force

model. The lateral displacement and rotational angle at the mid-span obtained from the proposed numerical model were, respectively, $63.5 \mathrm{~mm}$ and $0.86^{\circ}(0.015 \mathrm{rad})$ at a wind load of $3.8 \mathrm{kN} / \mathrm{m}$.

\section{Factors influencing the rollover instability of girders}

\section{Determination of influential factors}

The lateral instability of bridge girders depends mainly on the span length of the girder, variations of which can also change the section properties of the girder. Therefore, in this study, from the five types of Aashto standard I-beams, type IV, V and VI girders were selected to evaluate the lateral instability of precast concrete I-girders. Figure 8 shows the cross-sections of the three girders involved in this study. The elastomeric bearing pad for each girder was designed using method A of 


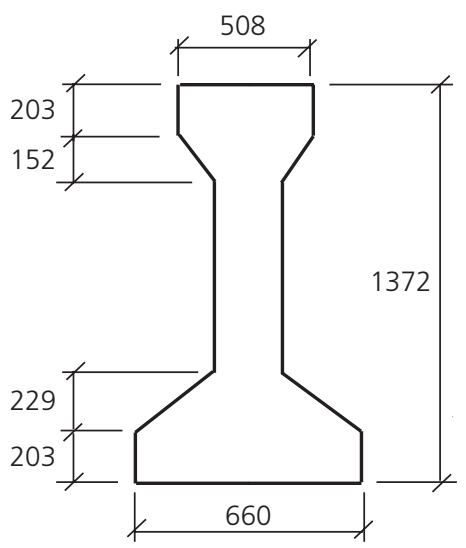

(a)

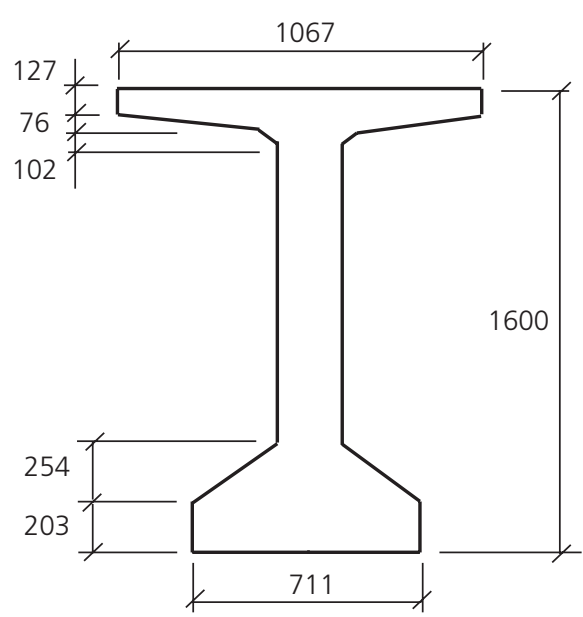

(b)

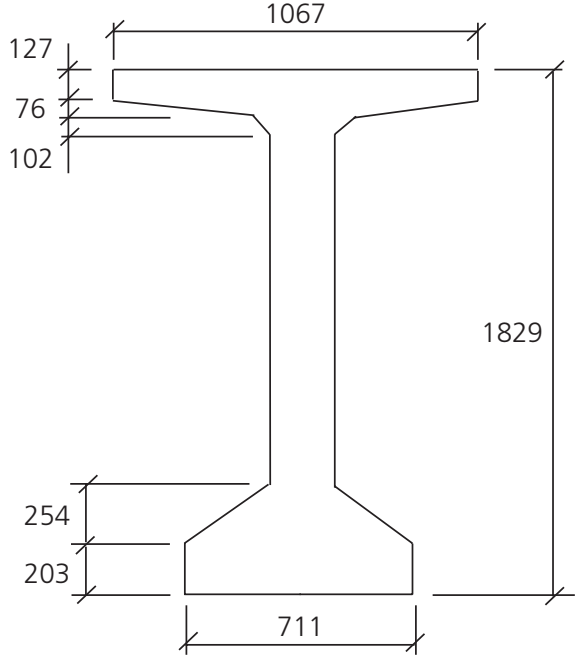

(c)

Figure 8. Cross-section of the Aashto girders: (a) type IV;

(b) type $\mathrm{V}_{\text {; }}(\mathrm{c}$ ) type VI (units in $\mathrm{mm}$ )

\begin{tabular}{|c|c|c|c|c|c|}
\hline \multirow[t]{2}{*}{ Girder } & \multirow[t]{2}{*}{ Length, $L: \mathrm{m}$} & \multirow[t]{2}{*}{$W_{\mathrm{b}} \times L_{\mathrm{b}} \times H_{\mathrm{b}}: \mathrm{mm}$} & \multirow[t]{2}{*}{ Shape factor, $S_{i}$} & \multicolumn{2}{|c|}{ Vertical stiffness, $k_{\mathrm{v}}: \mathrm{kN} / \mathrm{m}$} \\
\hline & & & & Below 0.03 & Above 0.03 \\
\hline \multirow[t]{3}{*}{ Type IV } & 30 & $550 \times 300 \times 45$ & $7 \cdot 64$ & 641667 & 825000 \\
\hline & 40 & $550 \times 300 \times 60$ & & 481250 & 618750 \\
\hline & 50 & $550 \times 300 \times 90$ & & 412500 & 412500 \\
\hline \multirow[t]{3}{*}{ Type V } & 30 & $600 \times 300 \times 45$ & $7 \cdot 87$ & 700000 & 900000 \\
\hline & 40 & $600 \times 300 \times 60$ & & 525000 & 675000 \\
\hline & 50 & $600 \times 300 \times 90$ & & 350000 & 450000 \\
\hline \multirow[t]{3}{*}{ Type VI } & 30 & $600 \times 300 \times 45$ & $7 \cdot 87$ & 700000 & 900000 \\
\hline & 40 & $600 \times 300 \times 60$ & & 525000 & 675000 \\
\hline & 50 & $600 \times 300 \times 90$ & & 350000 & 450000 \\
\hline
\end{tabular}

Table 1. Design of the elastomeric bearing pads

the Aashto LRFD specifications (Aashto, 2007, 2010), as described earlier. The width of the bearing pad was determined to be $550 \mathrm{~mm}$ for type IV and $600 \mathrm{~mm}$ for types V and VI, with a minimum clearance of $50 \mathrm{~mm}$ (GDoT, 2005). The size of the bearing pad was determined iteratively to satisfy the stress and deformation requirements of the Aashto LRFD specifications due to dead and live loads at the service limit. Table 1 lists the steel-reinforced bearing pads, with a 50 durometer hardness and a shear modulus of $0.7 \mathrm{MPa}$, determined for each girder due to dead and live loads at the service limit state. The compressive stress from the design load at the service state and the shape factor of the bearing pad were similar for the three girders, to eliminate the effects of the initial stress state and the shape factor of the bearing pad on the rollover instability of the girder.
The vertical stiffness of the bearing pad was calculated using the Aashto LRFD specifications (Aashto, 2007, 2010). As mentioned previously, from the stress-strain curve of an elastomer layer provided in the Aashto LRFD specifications, the modulus of elasticity of the bearing pad was defined as bilinear at 0.03 strain, $140 \mathrm{MPa}$ until 0.03 strain and $180 \mathrm{MPa}$ beyond this strain. The proposed numerical model was then used to examine the influence of span length and sectional properties of the precast concrete I-girder on the girder's lateral instability.

\section{Determination of critical load and deformations}

To examine the rollover instability of the precast concrete I-girders, the lateral displacement and rotational angles at 
the mid-span and the support were evaluated. Limits on the displacements and rotation angles are necessary not only for maintaining the rollover stability of girders during construction but also for establishing safe construction practices. Figures 9 and 10 show the wind load plotted against lateral displacement and rotational angle for the type IV, V and VI girders, ranging in length from $30 \mathrm{~m}$ to $50 \mathrm{~m}$, obtained from the proposed numerical method. As shown in the figures, the lateral displacements and rotational angles are initially proportional to the increase in wind load, and gradually increase due to the combined effects of the wind load and self-weight. The girders then reach rollover instability and finally collapse. As shown in Figures 9 and 10, the rotational angle changes more rapidly than the lateral displacement, combined with the lateral flexural movement. Therefore, to determine the critical wind load, lateral displacement and rotational angles that cause rollover instability prior to girder collapse, the initial and final tangents to the wind load-rotational angle curves (Figure 10) were used. Table 2 lists the critical wind load $\left(F_{\mathrm{cr}}\right)$, lateral displacement at the mid-span $\left(\delta_{\mathrm{cr}}^{0}\right)$ and rotational angle at the support $\left(\theta_{\mathrm{cr}}^{\mathrm{s}}\right)$ for the three types of girders, ranging in length from $30 \mathrm{~m}$ to $50 \mathrm{~m}$. With an increase in girder length, the critical wind load tends to decrease, while the critical lateral displacement and rotational angle increase.

\section{Evaluation of relationship between critical load and deformation and the influential factors}

Based on the determined critical wind loads, lateral displacements and rotational angles, this study examined the effects of the length and section of girders on their lateral instability. The section properties associated with lateral instability of a girder are the moment of inertia and torsional constant of the section. In addition, the critical load and displacement depend significantly on the length of the girder. Therefore, this study evaluated the correlation between the moment of inertia in the strong axis $\left(I_{x}\right)$, the moment of inertia in the weak axis $\left(I_{y}\right)$, the torsional constant $(J)$, length of the girder $(L)$, critical wind load $\left(F_{\mathrm{cr}}\right)$ and rotational angle at the $\operatorname{support}\left(\theta_{\mathrm{cr}}^{\mathrm{s}}\right)$.

The critical wind load and rotational angle at the support are strongly related to the length of the girder and hardly dependent on the sectional properties of the girder, as shown in Figure 11. The critical wind load and rotational angle at the support are almost linearly proportional to the length of the girder, with only a slight difference among the studied girders. That is, with increasing girder length, the critical wind load decreases and the rotational angle at the support increases, which correspond to negative and positive correlations, respectively, as shown in Figure 11. According to analysis of the trend lines (Figure 12), as the length of the girder changes, the critical wind load and rotational angle vary almost linearly, with coefficients of determination $\left(R^{2}\right)$ of 0.95 and 0.80 , respectively. The critical wind load decreased by approximately

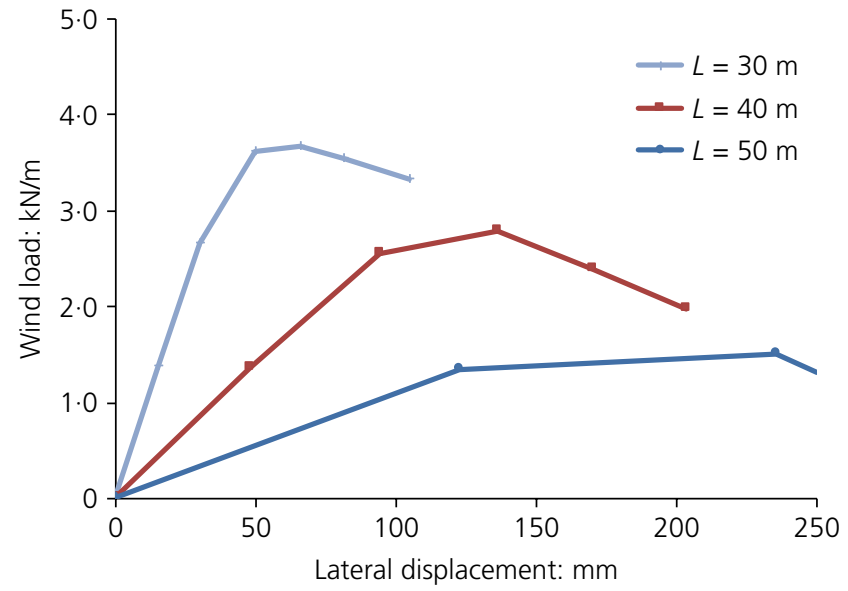

(a)

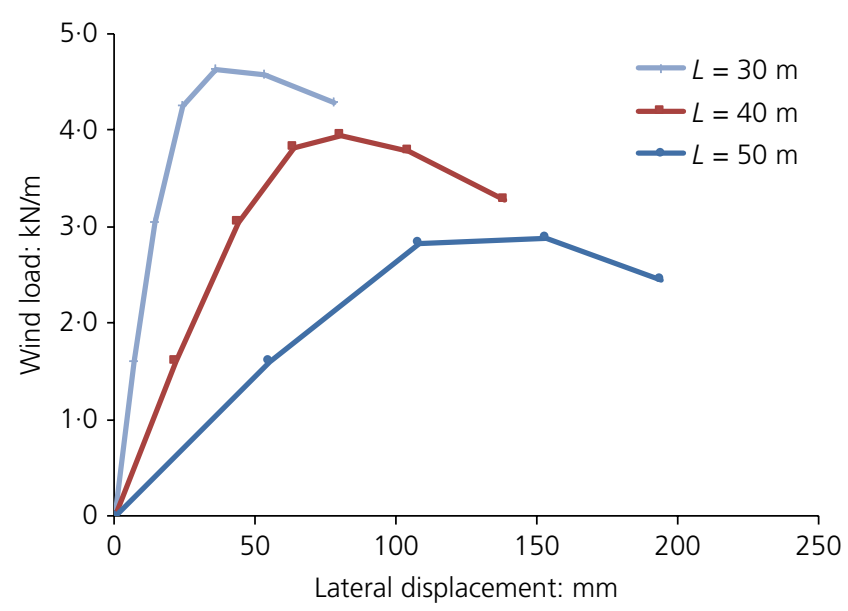

(b)

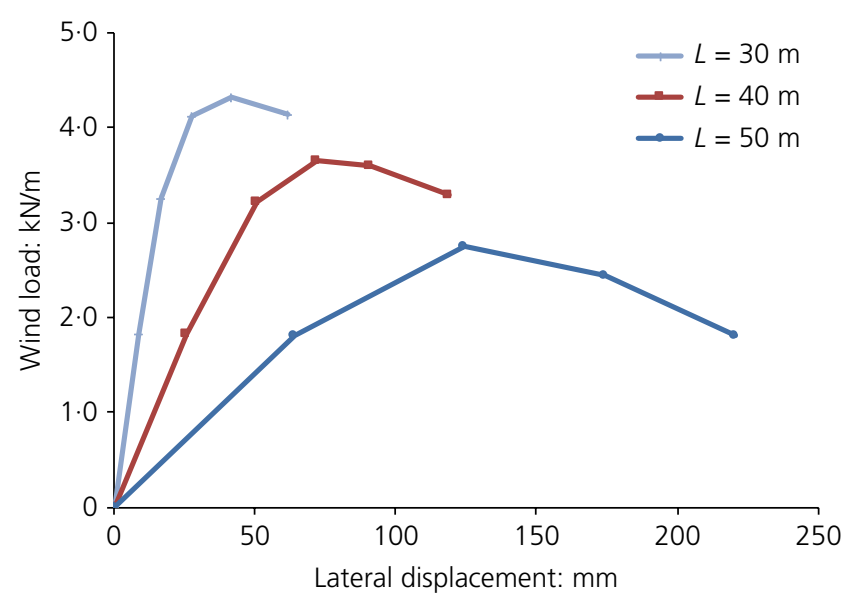

(c)

Figure 9. Variation in lateral displacement at mid-span with increasing girder length: (a) type $V$ girder; (b) type IV girder; (c) type VI girder

$1.2 \mathrm{kN} / \mathrm{m}$ per $10 \mathrm{~m}$ of girder length and the rotational angle increased by approximately $0.001 \mathrm{rad}$ per $10 \mathrm{~m}$ of girder length. 


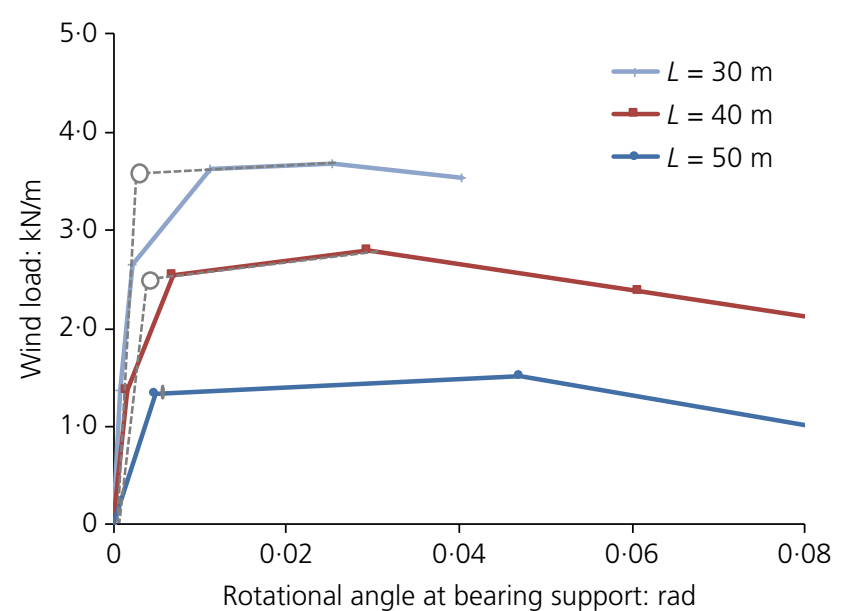

(a)

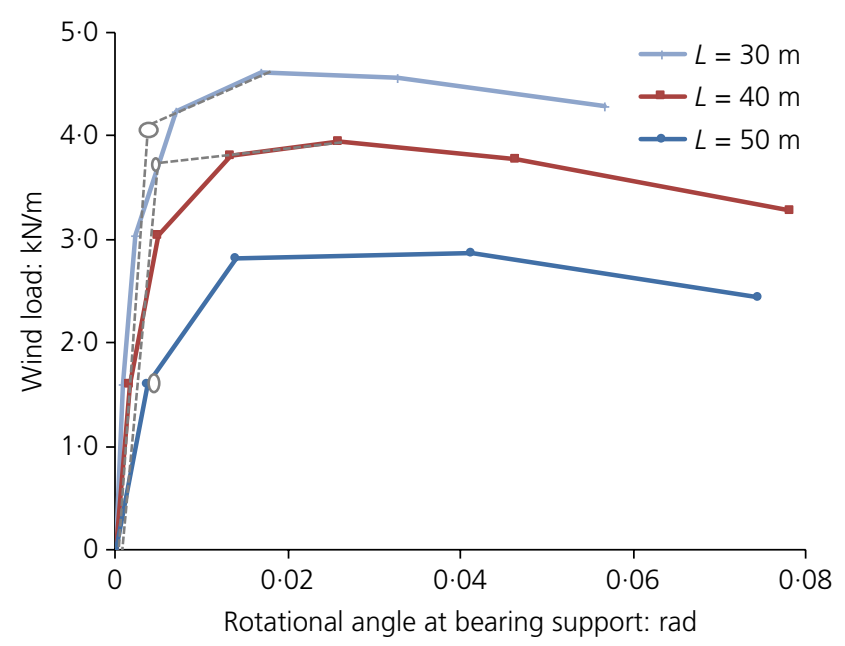

(b)

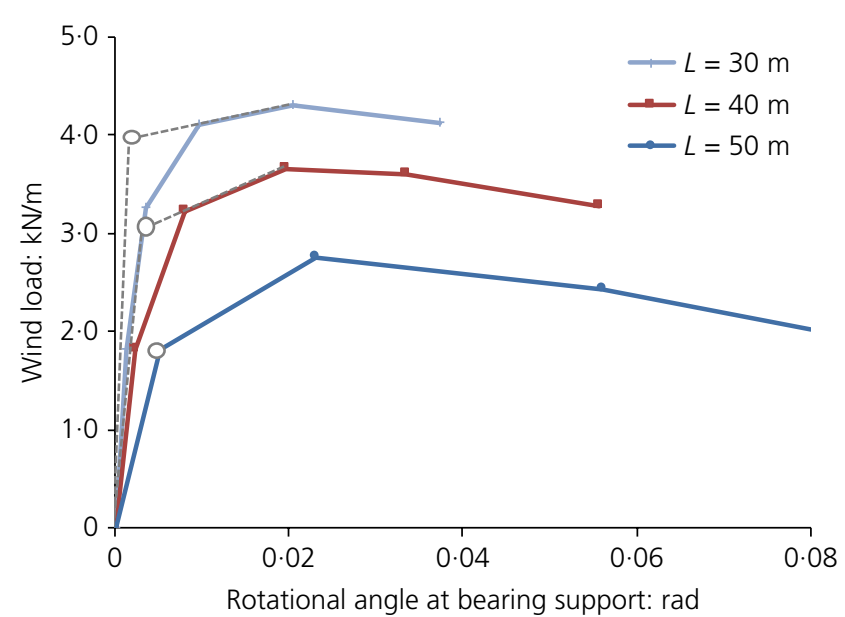

(c)

Figure 10. Variation in rotational angle at the bearing support with increasing girder length: (a) type $\mathrm{V}$ girder; (b) type IV girder; (c) type VI girder

\begin{tabular}{lccrcc} 
Girder & $L: \mathrm{m}$ & $F_{\mathrm{cr}}: \mathrm{kN} / \mathrm{m}$ & $\delta_{\mathrm{cr}}^{0}: \mathrm{mm}$ & $\theta_{\mathrm{cr}}^{0}: \mathrm{rad}$ & $\theta_{\mathrm{cr}}^{\mathrm{s}}: \mathrm{rad}$ \\
\hline Type IV & 30 & 3.59 & 39.1 & 0.003 & 0.002 \\
& 40 & 2.50 & 87.0 & 0.005 & 0.003 \\
\multirow{3}{*}{ Type V } & 50 & 1.34 & 122.6 & 0.009 & 0.005 \\
& 30 & 4.07 & 18.3 & 0.002 & 0.002 \\
& 40 & 2.87 & 39.4 & 0.003 & 0.003 \\
Type VI & 50 & 1.60 & 54.8 & 0.004 & 0.004 \\
& 40 & 3.99 & 18.6 & 0.003 & 0.003 \\
& 50 & 3.08 & 43.6 & 0.004 & 0.004 \\
& 50 & 1.81 & 64.3 & 0.005 & 0.005
\end{tabular}

Table 2. Critical wind load, lateral displacement, and rotational angles for the girders

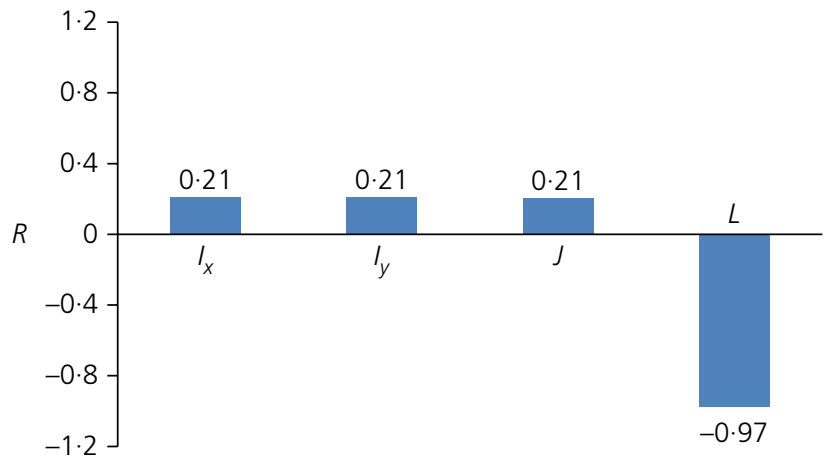

(a)

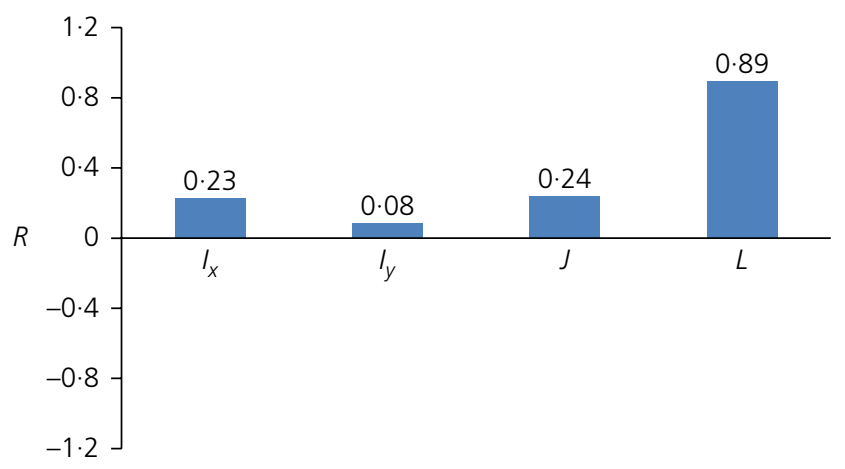

(b)

Figure 11. Correlation between the critical wind load and displacement and section properties of the girder: (a) critical wind load $\left(F_{\mathrm{cr}}\right)$; (b) critical rotational angle at the support $\left(\theta_{\mathrm{cr}}^{\mathrm{s}}\right)$

\section{Analytical procedure to determine rollover stability of girders subjected to wind load}

Based on the critical rotational angle at the support, the proposed analytical equation (Equation 7) was used to determine the critical wind load. Then, the critical lateral displacement caused by rotation of the support, the self-weight of the girder and wind load was calculated. Figure 13 compares the critical wind load and lateral displacement calculated using 


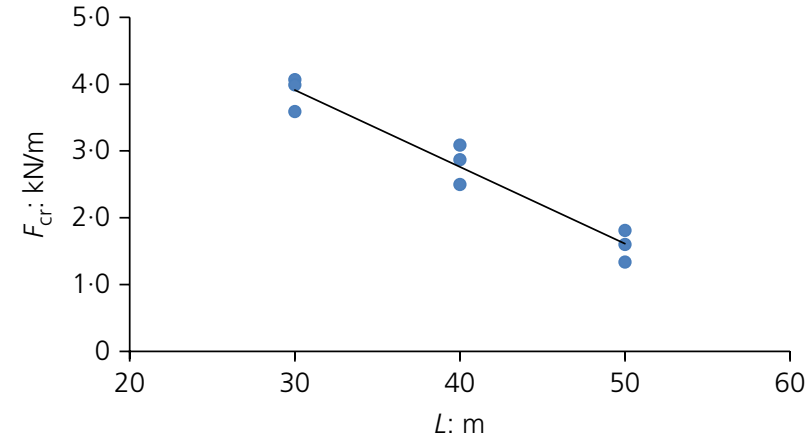

(a)

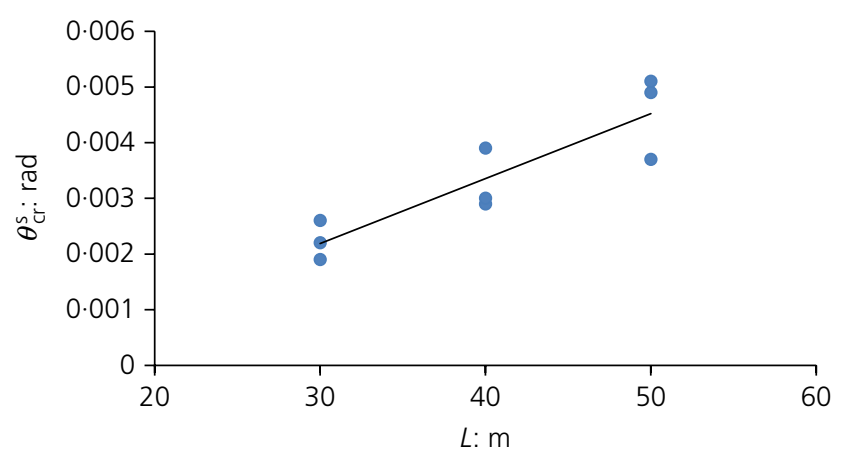

(b)

Figure 12. Variation in (a) critical wind load $\left(F_{\mathrm{cr}}\right)$ and (b) critical rotational angle at the support $\left(\theta_{\mathrm{cr}}^{\mathrm{s}}\right)$ with increasing girder length

Equation 7 and those obtained from the numerical analysis for the type IV, V and VI girders, ranging in length from $30 \mathrm{~m}$ to $50 \mathrm{~m}$. Both the critical wind load and lateral displacement calculated using the proposed equation agree well with the numerical results. In fact, the calculated values are somewhat on the safe side, with smaller values for the critical wind load and larger values for the critical lateral displacement than the numerical values. The root mean square error between the analytical and numerical results is $0.47 \mathrm{kN} / \mathrm{m}$ for the critical wind load and $14.3 \mathrm{~mm}$ for the lateral displacement.

Using the proposed equation, a chart was developed to determine the critical wind load given the self-weight of the girder for a reference condition (length of girder, centroid and lateral flexural rigidity of the cross-section and rotational stiffness of the bearing pad), as depicted in Figure 14. The critical wind load exponentially decreases with an increase in self-weight of the girder. Figures 15 and 16 show the effect of a change in rotational stiffness of the bearing pad and the length of the girder on the critical wind load. As the rotational stiffness and girder length increase, the critical wind load almost linearly increases and decreases, respectively. The critical wind load is also affected by the lateral flexural rigidity and the centroid distance of the section, as shown in Figure 17. The critical

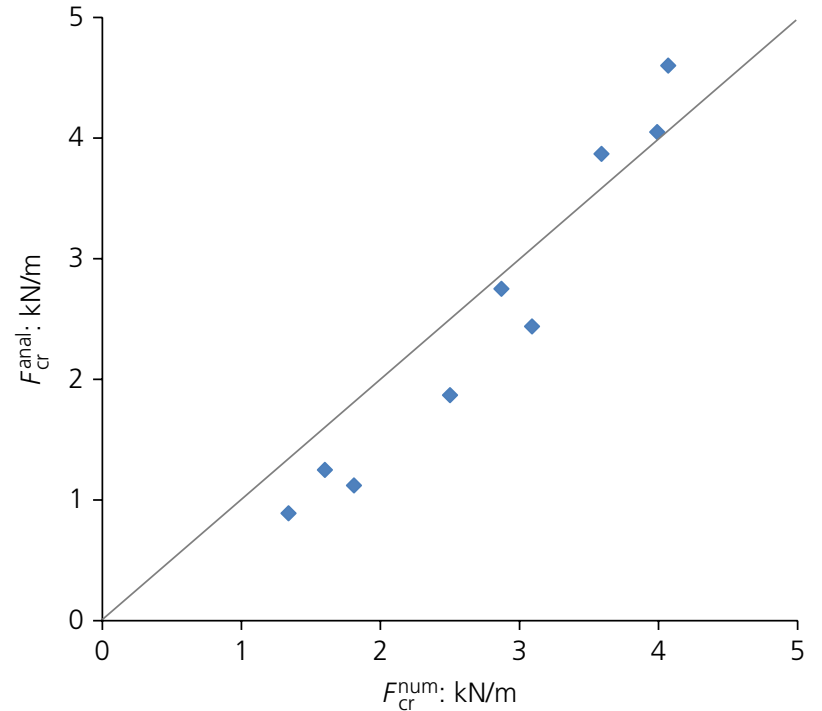

(a)

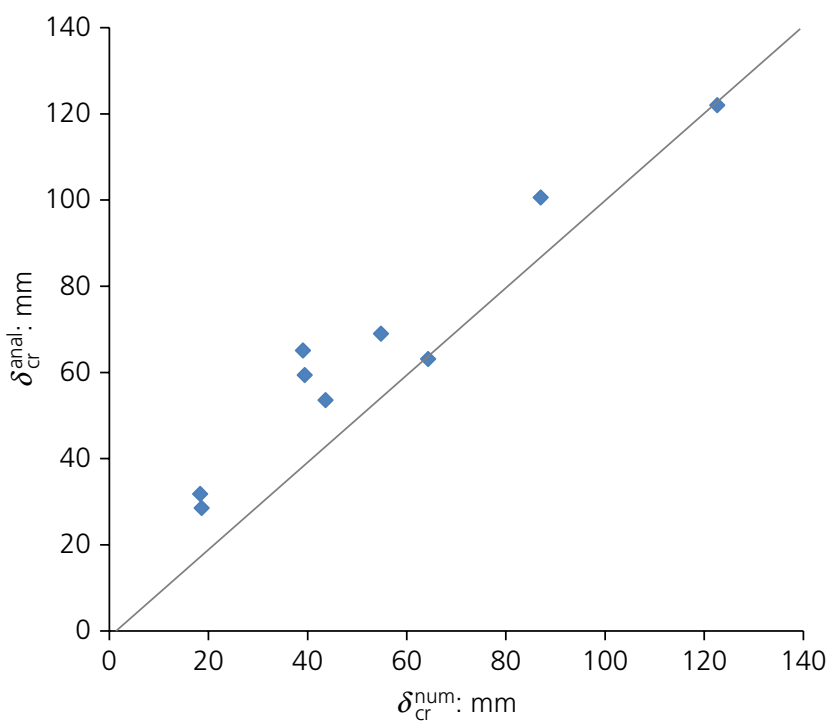

(b)

Figure 13. Comparison of (a) critical wind load and (b) critical lateral displacement obtained from the proposed analytical equations and numerical analysis

wind load increases with an increase in lateral flexural rigidity and a decrease in the centroid distance of the cross-section. Therefore, given the section and length of a bridge girder, the critical wind load can be obtained using the proposed analytical method or the charts shown in Figures 14-17. In addition to the critical wind load, the critical lateral displacement (basically determined from the critical wind load) and the critical rotational angle at the support $(0.001 \mathrm{rad}$ per $10 \mathrm{~m}$ length of the girder) could be applied as construction management values to retain rollover stability of a girder when it is being placed on an elastic bearing pad. 


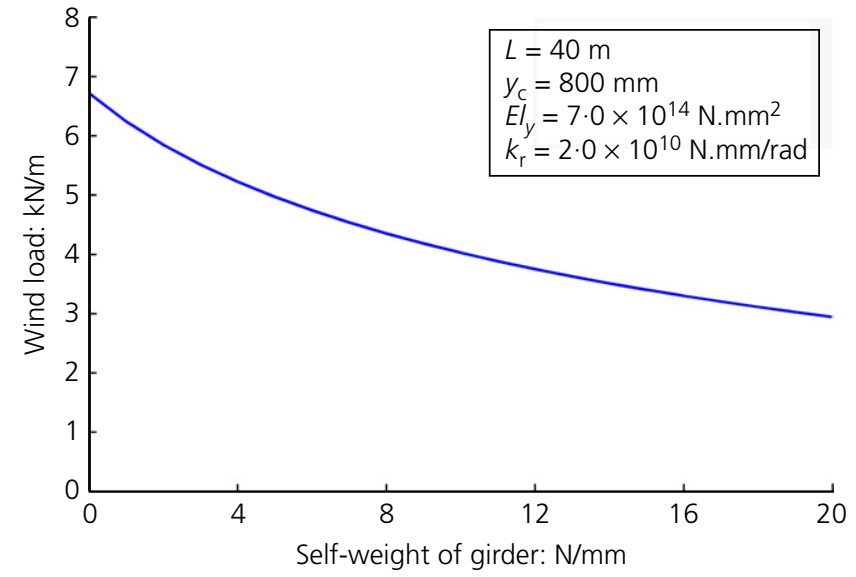

Figure 14. Relationship between critical wind load and self-weight of the girder

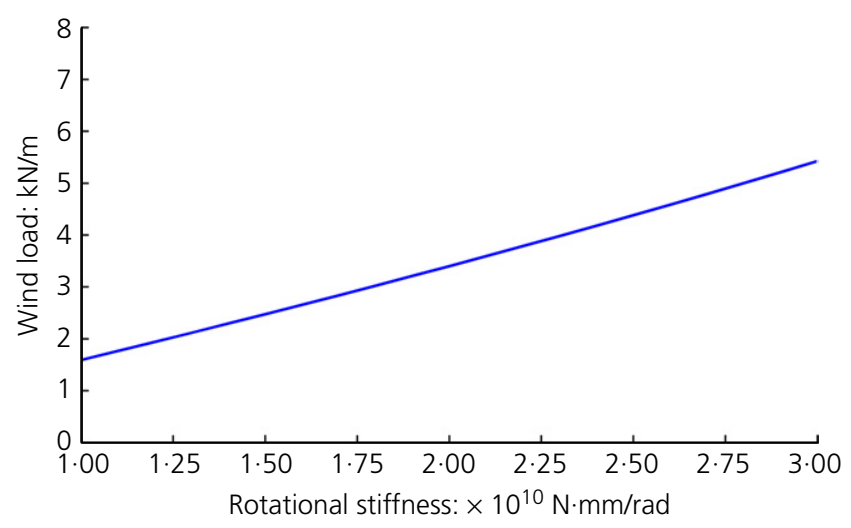

Figure 15. Variation in critical wind load with change in rotational stiffness of the bearing pad

\section{Worked problem of rollover stability for a super-Y (SY) beam}

The demand for long-span concrete bridge girders has resulted in the production of standard precast beams, which can improve material quality and structural performance as well as facilitate construction and design processes. In the USA, long precast beams, such as Aashto standard beams, have been proposed for spans up to about $55 \mathrm{~m}$. In the UK, standard beams called $\mathrm{M}$ and $\mathrm{Y}$ beams are produced for medium- and longspan bridges ranging in length from approximately $15 \mathrm{~m}$ to $30 \mathrm{~m}$. In addition, super-Y (SY) beams have been developed from standard $\mathrm{Y}$ beams for longer span bridges ranging from approximately $25 \mathrm{~m}$ to $40 \mathrm{~m}$ (Burgoyne and Stratford, 1999). The SY beam is the largest series in the standard precast beams currently manufactured in the UK (Burgoyne and Stratford, 2001). Among the SY beam sections, SY6 is used to design the longest beam available, up to $40 \mathrm{~m}$ in length. A worked problem for an SY6 beam is therefore provided to

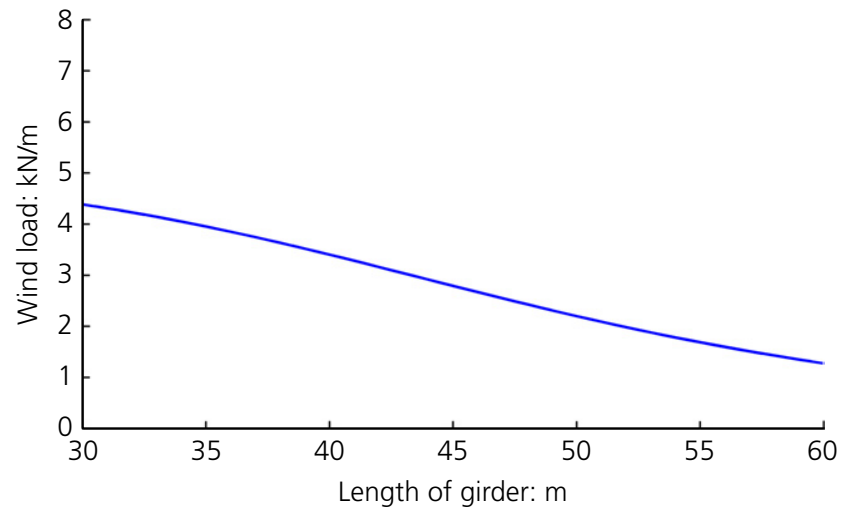

Figure 16. Variation in critical wind load with change in girder length

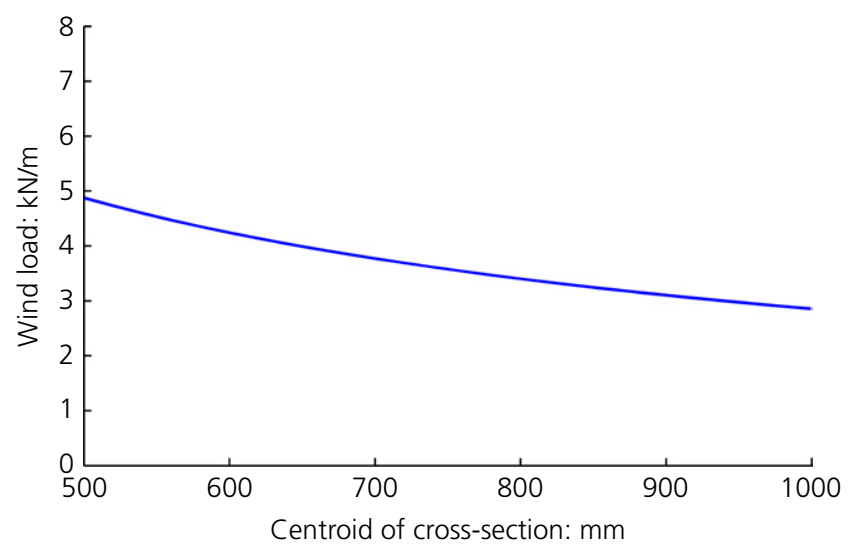

(a)

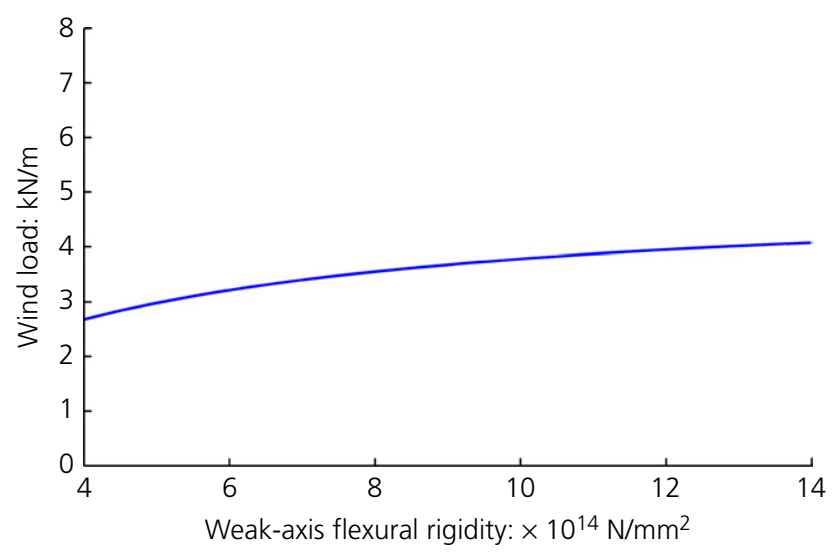

(b)

Figure 17. Variation in critical wind load with change in (a) the centroid and (b) the flexural rigidity of the cross-section

calculate the critical load and displacements, which can be used as a management value for securing the rollover stability of the beam. Figure 18 shows the cross-section of the SY6 beam and the section properties are given in Table 3 . 


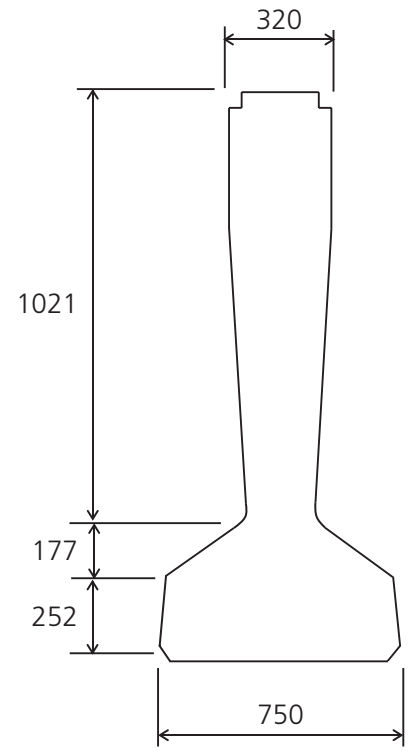

Figure 18. Cross-section of the SY6 beam (units in $\mathrm{mm}$ )

Self-weight, $w$ : N/mm (calculated using

density of $25 \mathrm{kN} / \mathrm{m}^{3}$ )

Height of centroid, $y_{c}: \mathrm{mm}$

Cross-section area, $A: \mathrm{mm}^{2}$

Strong-axis moment of inertia, $l_{x}: \mathrm{mm}^{4}$

Weak-axis moment of inertia, $l_{y}: \mathrm{mm}^{4}$

Table 3. Section properties of the SY6 beam shown in Figure 18

Based on a defined, given SY6 beam section, the elastomeric bearing pad, commonly used to support precast concrete bridge beams, is designed according to the design loads at the service limit state, as discussed earlier in the paper. The width of the bearing pad was assumed to be $500 \mathrm{~mm}$ with a minimum clearance of $125 \mathrm{~mm}$ on both sides (Macrete, 2016). Subsequently, the length and height of the bearing pad were determined according to the design dead and live loads. For a $35 \mathrm{~m}$ long SY6 beam, the steel-reinforced elastomeric bearing pad was designed to be $500 \mathrm{~mm}$ wide, $300 \mathrm{~mm}$ long and $53 \mathrm{~mm}$ high. The vertical stiffness of the bearing pad was then calculated using Equation 12. In the calculation of the vertical stiffness, the modulus of elasticity, which is somewhat different among the design standards, was determined using EN 1337-3 (CEN, 2005). The deformation of the elastomeric bearing pad under vertical compression can be divided into the deformations caused by the elastomer rubber and Poisson's effect. Therefore, the modulus of elasticity of the elastomeric bearing pad was calculated from the parallel combination of the apparent modulus of elasticity, $E_{\mathrm{ap}}$, and the bulk modulus of elasticity, $E_{\mathrm{b}}$

14. $\frac{1}{E_{\mathrm{s}}}=\frac{1}{E_{\mathrm{ap}}}+\frac{1}{E_{\mathrm{b}}}$

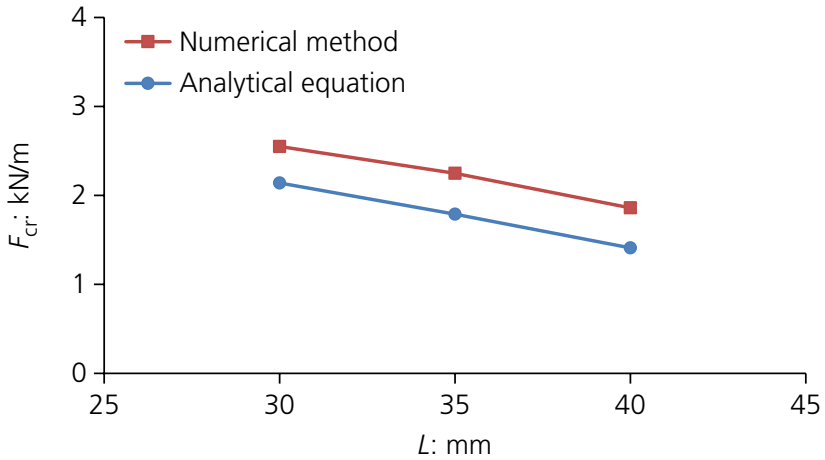

(a)

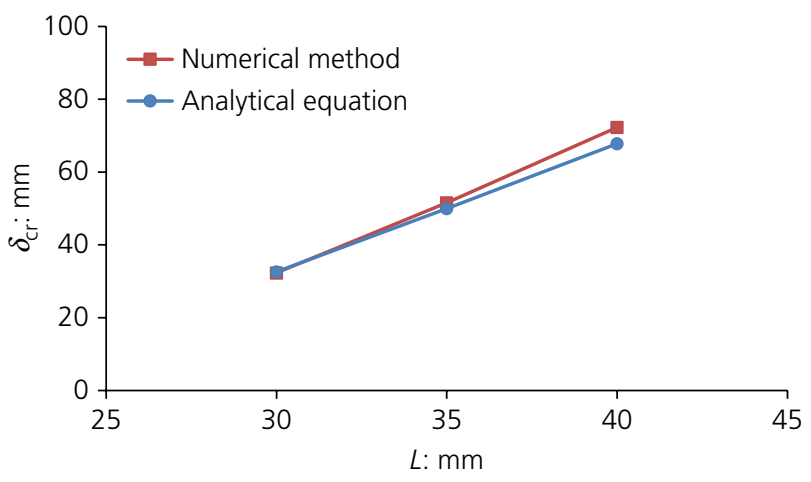

(b)

Figure 19. Comparison of the critical values of the SY 6 beam obtained from the proposed analytical equation and the numerical method: (a) critical wind load; (b) critical lateral displacement at mid-span

where $E_{\mathrm{ap}}=5 G S_{i}^{2}$, and $E_{\mathrm{b}}=2000 \mathrm{MPa}$. The shear modulus of the elastomer, $G$, was taken as $0.7 \mathrm{MPa}$, and the shape factor of the bearing pad, $S_{i}$, was calculated using Equation 9 based on the size of the elastomeric bearing pad. For the SY6 beam $35 \mathrm{~m}$ long, the vertical and rotational stiffness were calculated to be approximately $5.46 \times 10^{5} \mathrm{kN} / \mathrm{m}$ and $1 \cdot 138 \times 10^{4} \mathrm{kN} \cdot \mathrm{m} / \mathrm{rad}$, respectively.

With the defined stiffness of the bearing pad and the geometric and sectional properties of the beam, Equation 7 was used to determine the critical wind load and lateral displacement at the mid-span, which could be applied as a management value for securing the rollover stability of the beam. The critical rotational angle at the support, which is required for the solution of Equation 7, was taken as $0.001 \mathrm{rad}$ per $10 \mathrm{~m}$ length of the girder, as discussed in the previous section. For comparison, the proposed numerical method was also used to determine the critical wind load and lateral displacement at the mid-span: the values obtained using Equation 7 were $1.79 \mathrm{kN} / \mathrm{m}$ and $50.0 \mathrm{~mm}$, respectively, which are 0.84 and 1.01 times those obtained from the numerical method, respectively. In addition, with an increase in beam length from 30 to $40 \mathrm{~m}$, the critical wind load decreased almost linearly and the critical lateral displacement increased, as 


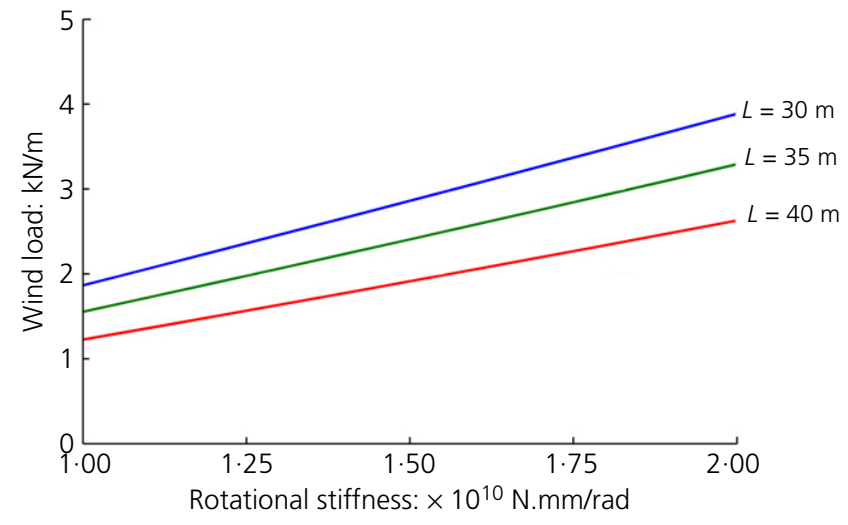

Figure 20. Relationship between critical wind load, change in beam length and rotational stiffness of the bearing pad for the SY6 beam

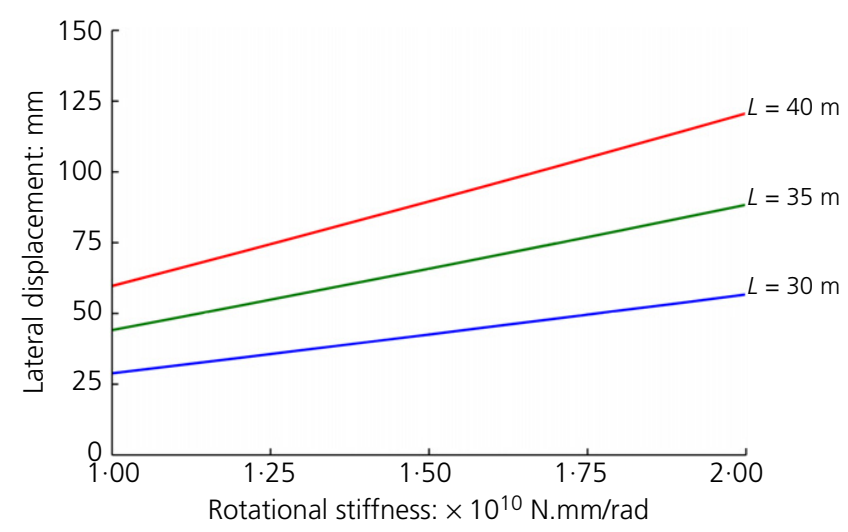

Figure 21. Relationship between critical lateral displacement at mid-span with change in beam length and rotational stiffness of the bearing pad for the SY6 beam

shown in Figure 19. Similar to the trend presented by the standard Aashto beams, the SY6 beam also showed that values calculated from the analytical equation were a little smaller for the critical wind load and larger for the critical lateral displacement than the numerical values.

Finally, for the SY6 beam, the proposed analytical equation was used to construct Figure 20, which can be used to determine a management value for design and construction according to changes in the beam length and the stiffness of the bearing pad. In addition, Figure 21 can be used to determine the critical lateral displacement at the mid-span for another management value for the rollover stability of an SY6 beam with variance in the beam length and the bearing stiffness.

\section{Conclusions}

Analytical and simplified numerical studies were performed to investigate the lateral behaviour of precast concrete girders and to determine the critical wind load, lateral displacement and rotational angle that could induce rollover instability in girders on elastomeric bearing pads, particularly during construction. The loading condition considered in this study was the stage when a girder is placed on an elastic bearing pad and is subjected to lateral wind load, which is considered a significant external force to induce rollover instability of a precast girder.

The proposed numerical method, based on $3 \mathrm{D}$ beam and link elements, involved three sequential analyses: $(a)$ static analysis to generate the camber of the girder produced by a prestressing force; $(b)$ non-linear analysis with the elastomeric bearing supports and the self-weight of the girder; $(c)$ non-linear analysis using the lateral wind load, which is considered a primary factor that could induce the lateral instability of the girder. The results obtained from the proposed numerical method agreed very well with those of the 3D FE models using solid and shell elements.

The values of critical wind load, lateral displacement and rotational angle that cause rollover instability to become the governing mode of failure of the girder were then determined. In addition, the influence of the length and section properties of the girder on rollover instability was assessed. The critical wind load and rotational angle at the support were found to be strongly related to the length of the girder, but not to the sectional properties of the girder.

With the determined critical rotational angle, an analytical equation was developed to determine the critical wind load and lateral displacement caused by rotation of the support, the self-weight of the girder, and the wind load. The critical wind load and lateral displacement calculated using the proposed equation agreed well with the numerical results. In addition, charts are provided that can be used to determine the critical wind load and lateral displacement of a bridge girder, given the section properties and length of the girder.

The proposed analytical method can thus be effectively applied to evaluate the lateral behaviour and instability of precast concrete girders and provide management values to retain the rollover stability of a girder on an elastic bearing pad, particularly during construction.

\section{Acknowledgements}

This study was supported by a Basic Science Research Program through the National Research Foundation of Korea (NRF) funded by the Ministry of Science, ICT \& Future Planning (NRF-2014R1A1A1005992).

\section{REFERENCES}

Aashto (American Association of State Highway and Transportation Officials) (2004) Aashto Bridge Construction Specifications: 2006 and 2007 Interim Revisions. Aashto, Washington, DC, USA. 
Aashto (2007) Aashto LRFD Bridge Design Specifications. Aashto, Washington, DC, USA.

Aashto (2010) Aashto LRFD Bridge Design Specifications. Aashto, Washington, DC, USA.

Atta AM and El-Shafiey TF (2014) Strengthening of RC dapped-end beams under torsional moment. Magazine of Concrete Research 66(20): 1065-1072, http://dx.doi.org/ 10.1680/macr.14.00067.

Barsoum RS and Gallagher RH (1970) Finite element analysis of torsional and torsional flexural stability problems. International Journal of Numerical Methods in Engineering 2(3): 335-352.

Burgoyne CJ and Stratford TJ (1999) Lateral stability of long precast concrete beams. Proceedings of the Institution of Civil Engineering - Structures and Buildings 134(2): 159-168, http://dx.doi.org/10.1680/istbu.1999.31383.

Burgoyne CJ and Stratford TJ (2001) Lateral stability of long-span prestressed concrete beams on flexible bearings. Structural Engineering 79(6): 23-26.

CEN (European Committee for Standardization) (2005) EN 1337-3 Structural bearing part 2: elastomeric bearings. CEN, Brussels, Belgium.

FDoT (Florida Department of Transportation) (1997) Structures Design Guidelines. Structures Design Office, Tallahassee, FL, USA.

GDoT (Georgia Department of Transportation) (2005) Bridge and Structures Design Policy Manual. GDoT, Atlanta, GA, USA.

Guiglia M, Debernardi PG and Taliano M (2013) Calculation of the ultimate stress of unbonded tendons in prestressed concrete members considering the rotation capacity. Magazine of Concrete Research 65(1): 14-26, http://dx.doi.org/10.1680/macr.11.00197.

Han TH, Won DH, Kim S and Kang YJ (2013) Performance of a double-skinned composite tubular column under lateral loading: analysis. Magazine of Concrete Research 65(2): 121-135, http://dx.doi.org/10.1680/macr.12.00024.

Heiza KM (2013) New finite-element approach for reinforced concrete beams. Magazine of Concrete Research 65(1): 1-13, http://dx.doi.org/10.1680/macr.11.00191.

Hou J, Song L and Liu H (2016) Progressive collapse of RC frame structures after a centre column loss. Magazine of Concrete Research 68(8): 423-432, http://dx.doi.org/ 10.1680/jmacr.15.00160.

Hurff JB and Kahn LF (2012) Rollover stability of precast, prestressed concrete bridge girders with flexible bearings. PCI Journal 57(4): 96-107.

Jones MR, Ozlutas K and Zheng L (2016) Stability and instability of foamed concrete. Magazine of Concrete Research 68(11): 542-549, http://dx.doi.org/10.1680/macr. 15.00097.

Kim MS, Scanlon A, Kang J and Lee YH (2014) Torsional behavior of prestressed concrete girder with precast box segments. Magazine of Concrete Research 66(11): 576-584, http://dx.doi.org/10.1680/macr.13.00086.
Laszlo G and Imper RR (1987) Handling and shipping of long span bridge beams. PCI Journal 34(1): 86-101.

Lee JH (2012a) Behavior of precast prestressed concrete bridge girders involving thermal effects and initial imperfections during construction. Engineering Structures 42: 1-8.

Lee JH (2012b) Investigation of extreme environmental conditions and design thermal gradients during construction for prestressed concrete bridge girders. ASCE Journal of Bridge Engineering 17(3): 547-556.

Lee JH and Kalkan I (2012) Analysis of thermal environmental effects on precast, prestressed concrete bridge girders: temperature differentials and thermal deformations Advances in Structural Engineering 15(3): 447-459.

Lee C, Shin S and Lee S (2015) Modelling of load-deflection of concrete beams internally prestressed with unbonded CFRP tendons. Magazine of Concrete Research 67(13): 730-746, http://dx.doi.org/10.1680/macr.14.00367.

Li JZ, Hung KC and Cen ZZ (2002) Shell element of relative degree of freedom and its application on buckling analysis of thin-walled structures. Thin-Walled Structures 40(10): $865-876$.

Macrete (2016) SY Prestressed Beam Technical Details. Macrete Ireland Ltd, Antrim, UK. See http://www.macrete. com/downloads/ (accessed 12/07/2016).

Mast RF (1989) Lateral stability of long prestressed concrete beams: Part 1. PCI Journal 32(6): 34-53.

Mast RF (1993) Lateral stability of long prestressed concrete beams: Part 2. PCI Journal 38(1): 70-88.

Mullapudi TRS and Ayoub A (2013) Non-linear analysis of reinforced concrete walls under three-dimensional loading. Magazine of Concrete Research 65(3): 172-184, http://dx.doi.org/10.1680/macr.12.00038.

Najafian HA, Vollum R and Fang L (2013) Comparative assessment of finite-element and strut and tie based design methods for deep beams. Magazine of Concrete Research 65(16): 970-986, http://dx.doi.org/10.1680/macr.13.00006.

Oesterle RG, Sheehan MJ, Lotfi HR, Corley WG and Roller JJ (2007) Investigation of Red Mountain Freeway Bridge Girder Collapse. CTL Group, Skokie, IL, USA, Final report (project no. 262291).

PCI (Precast/Prestressed Concrete Institute) (2003) PCI Bridge Design Manual. PCI, Chicago, IL, USA.

Rengarajan G, Aminpour MA and Knight NF (1985) Improved assumed-stress hybrid shell element with drilling degrees of freedom for linear stress, buckling and free vibration analyses. International Journal of Numerical Methods in Engineering 38(11): 1917-1943.

Talbot M and Dhatt G (1987) Three discrete Kirchhoff elements for shell analysis with large geometrical non-linearities and bifurcations. Engineering Computations 4(1): $15-22$

TxDoT (Texas Department of Transportation) (2012) LRFD Bridge Manual. TDoT, Austin, TX, USA.

Vidigal de Lima MC and El Debs MM (2005) Numerical and experimental analysis of lateral stability in precast concrete 
beams. Magazine of Concrete Research 57(10): 635-647, http://dx.doi.org/10.1680/macr.2005.57.10.635.

WisDoT (Wisconsin Department of Transportation) (2014)

LRFD Bridge Manual. WisDoT, Madison, WI, USA.

Yazdani N, Eddy SM and Cai CS (2000) Effect of bearing pads

on precast prestressed concrete bridges. ASCE Journal of Bridge Engineering 5(3): 224-232.
Yazdani N, Eddy SM and Cai CS (2003) Validation of Aashto bearing stiffness for standard precast concrete bridge girders. ACI Structural Journal 97(3): 436-443.

Yooprasertchai E, Hadiwijaya I and Warnitchai P (2016) Seismic performance of precast concrete rocking walls with buckling restrained braces. Magazine of Concrete Research 68(9): 462-476, http://dx.doi.org/10.1680/jmacr.15.00237.

\section{HOW CAN YOU CONTRIBUTE?}

To discuss this paper, please submit up to 500 words to the editor at journals@ice.org.uk. Your contribution will be forwarded to the author(s) for a reply and, if considered appropriate by the editorial board, it will be published as a discussion in a future issue of the journal. 